\title{
INTOXICAÇÃO ESPONTÂNEA POR Combretum glaucocarpum Mart. [sin.: Thiloa glaucocarpa (Mart.) Eichler] (Combretaceae) EM BOVINOS
}

\section{SPONTANEOUS POISONING BY Combretum glaucocarpum Mart. [sin.: Thiloa glaucocarpa (Mart.) Eichler] (Combretaceae) IN CATTLE}

\author{
Michel Abdalla Helayel ${ }^{1 *}$ \\ Adriano Tony Ramos ${ }^{2}$ \\ André Valério Goloni ${ }^{1}$ \\ Angela Patricia Medeiros Veiga ${ }^{2}$ \\ Sandro Estevan Moron ${ }^{1}$ \\ Rodney Haulien Oliveira Viana ${ }^{1}$ \\ Cícero Pereira de Carvalho Júnior ${ }^{1}$ \\ 1Universidade Federal do Tocantins, Araguaína, TO, Brasil \\ 2Universidade Federal de Santa Catarina, Curitibanos, SC, Brasil \\ *Autor para correspondência - michel_abdallavet@yahoo.com.br
}

\begin{abstract}
Resumo
O presente trabalho tem por objetivo descrever, pela primeira vez no Estado do Tocantins, as características epidemiológicas, clínicas e patológicas de um surto de intoxicação espontânea por Combretum glaucocarpa em bovinos. De um lote de 200 bovinos acessíveis à planta, 70 animais chegaram a óbito. Os sinais observados foram edema na região posterior da coxa e inguinal, períneo, escroto e ventre do abdômen, tórax e barbela; fezes escuras e fétidas; emagrecimento e pêlos ásperos. O curso clínico variou de 3 a 20 dias. As concentrações séricas de ureia e creatinina e as atividades séricas de alanino-aminotransferase e aspartatoaminotransferase estavam elevadas nos dez animais avaliados. As lesões observadas foram grande quantidade de transudato na cavidade abdominal, tórax e saco pericárdico. Notou-se edema na bexiga, tecidos perirenais e na subserosa da vesícula biliar, junto à sua inserção com o fígado. Este estava aumentado, com bordos arredondados, congesto e azulado. Petéquias e equimoses foram observadas no epicárdio, miocárdio, mucosa da traqueia, omento, serosa do rúmen, vesícula urinária e testículos. Áreas de sufusões foram observadas no encéfalo. Na histopatologia, visualizou-se degeneração hidrópica centrolobular leve no fígado e, no rim, focos de hemorragia na junção corticomedular com degeneração tubular leve. Encontraram-se células epiteliais necróticas e cilindros hialinos em alguns túbulos renais. É a primeira descrição por C. glaucocarpum em bovinos no Tocantins.
\end{abstract}

Palavras-chave: nefrose tubular tóxica; plantas nefrotóxicas; sipaúba; toxicologia.

\begin{abstract}
The present study aimed to describe, for the first time in Tocantins State, the epidemiological, clinical, and pathological aspects of an outbreak of Combretum glaucocarpa poisoning in cattle. From a herd of 200 cattle that had access to the plant, 70 animals died. The signs were swelling of the posterior thigh, groin, perineum, scrotum, ventral abdomen, chest, and barb; dark and fetid stools; marked weight loss, and rough hair. The
\end{abstract}


clinical course ranged from 3 to 20 days. The serum activities of alanine aminotransferase and aspartate amininotransferase and the serum concentrations of urea and creatinine were markedly elevated in all the ten animals examined. The gross lesions consisted of large amouts of transudate in the peritoneal, pleural, and pericardial cavities. Edema was also seen in the urinary bladder, perirenal tissue and gallbladder subserosa at its insertion to the liver. The liver was enlarged, congested, and bluish. Petechiae and ecchymosis were observed in the epicardium, myocardium, tracheal mucosa, omentum, ruminal serosa, urinary bladder, and testicles. Suffusions were detected in the brain. Histopathology of the liver revealed mild centrilobular degeneration. In the kidney, hemorrhagic foci in corticomedullary junction with mild tubular degeneration were observed. Additionally, some renal tubules had necrotic epithelial cells and hyaline casts. It is the first report of poisoning by $C$. glaucocarpum in cattle in Tocantins.

Keywords: nephrotoxic plants; Sipaúba; toxicology; tubular nephrosis.

Recebido em: 17 novembro 2014

Aceito em: 07 abril 2017

\section{Introdução}

Combretum glaucocarpa Mart. é uma árvore arbustiva pertencente à família Combretaceae, considerada a planta nefrotóxica mais importante do Brasil. É observada na caatinga, no litoral do Nordeste, principalmente nos Estados do Piauí e do Ceará, no oeste da Bahia e na região oeste de Minas Gerais, como evidencia Tokarnia et al. ${ }^{(1)}$. Nessas regiões, a planta é conhecida como "sipaúba" ou "vaqueta", e tem sido responsável por causar uma doença em bovinos designada pelos nomes populares de "popa-inchada", "venta-seca", "malda-rama" ou "mal-da-rama-murcha". Segundo Tokarnia et al. ${ }^{(2)}$, essa enfermidade tem sido observada anualmente, e sob a forma de surtos, sempre no início das estações chuvosas. Os bovinos só adoecem por um período de cinco a oito dias, entre o $10^{\circ}$ e $25^{\circ}$ dia após a primeira chuva, em consequência do desenvolvimento mais rápido da $C$. glaucocarpa em relação às outras plantas da região. A incidência da doença varia de ano para ano, em consequência da maneira como se inicia a estação chuvosa, segundo as pesquisas de Riet-Correa et al. ${ }^{(3)}$ e Tokarnia et al. ${ }^{(1)}$.

A doença é carcaterizada por edemas subcutâneos, sobretudo na parte posterior da coxa, períneo, escroto e por vezes se estendendo por toda a parte ventral do abdome, tórax e barbela. Outras manifestações relatadas são anorexia com emagrecimento progressivo, atonia ruminal, fezes ressecadas e recobertas por muco, às vezes com estrias de sangue, ou ainda enegrecidas e com cheiro muito desagradável; focinho ressecado, com secreção catarral, às vezes com sangue e posterior formação de crostas nas narinas; pelos ásperos, andar lento e arrastado e polidipsia; alguns animais desenvolvem hipotermia; a urina tem cor normal. $\mathrm{O}$ índice de letalidade é de aproximadamente $75 \%$, com base nos trabalhos de Tokarnia et al. ${ }^{(2)}$. Silva ${ }^{(4)}$ relatou o aumento dos níveis séricos de ureia, creatinina e bilirrubina total e presença de albumina, sais biliares e cilindros na urina em bovinos intoxicados experimentalmente pela C. glaucocarpa.

Macroscopicamente, as principais alterações observadas consistem em edemas subcutâneos, derrames serosos nas cavidades abdominal, torácica e no saco pericárdico, edema no tecido perirrenal e rins pálidos com pontos avermelhados na superfície e ao corte. São ainda encontradas petéquias, equimoses e sufusões nas serosas, no epicárdio e endocárdio e nas mucosas da traqueia, abomaso, intestino delgado e grosso. $\mathrm{O}$ fígado quase sempre apresenta lobulação evidente. As alterações histológicas mais significativas e constantes são encontradas nos rins, sob a forma de necrose tubular tóxica, caracterizada por necrose coagulativa de boa parte dos túbulos do córtex renal. As células epiteliais são transformadas em massas eosinofílicas amorfas que preenchem os túbulos, externamente delimitados apenas pela membrana basal. Por vezes, observa-se o 
epitélio finamente vacuolizado, com aspecto espumoso. As alças de Henle podem apresentar degeneração gordurosa (demonstrada pela coloração de Sudan III). Túbulos uriníferos podem exibir dilatação tanto no córtex quanto na medula, degeneração em gotas hialinas em algumas células epiteliais e, às vezes, edema intersticial no córtex renal. Tokarnia et al. ${ }^{(2)}$ relataram também necrose paracentral no fígado e áreas de necrose difteróide nas vias aéreas superiores.

O presente trabalho tem por objetivo descrever, pela primeira vez no Estado do Tocantins, as características epidemiológicas, clínicas e patológicas de um surto de intoxicação espontânea por Combretum glaucocarpa em bovinos.

\section{Material e Métodos}

O surto ocorreu no incício do mês de outubro de 2011, em uma propriedade rural de criação extensiva de bovinos Nelore no município de Paraíso do Tocantins, região central do Tocantins (latitude $-10^{\circ} 10^{\prime} 34 "$, longitude $-48^{\circ} 52^{\prime} 00^{\prime \prime}$, altitude 387 metros). No momento da visita, foi realizada avaliação visual do lote acometido. Dez animais doentes foram identificados com números de 1 a 10 e avaliados clínicamente. Procedeu-se à coleta de sangue através de punção da veia jugular para realização de bioquímica dos níveis séricos de ureia, creatinina, proteínas plasmáticas totais (PPT), albumina e globulina e das atividades séricas de alanina aminotransferase (ALT) e aspartato aminotransferase (AST). O histórico clínico e epidemiológico foi obtido com o proprietário e o médico veterinário responsável pelo atendimento inicial. $\mathrm{O}$ bovino $\mathrm{N}^{\circ} 6$ morreu naturalmente logo após o exame clínico e foi imediatamente necropsiado. Foram coletados fragmentos dos principais órgãos, fixados em formol tamponado a 10\%, processados rotineiramente para histopatologia e corados com hematoxilina-eosina (HE).

\section{Resultados}

O proprietário havia colocado um lote de 200 bovinos machos de 15 a 20 meses, recém-chegados do Estado de Goiás, em um piquete de Brachiaria brizantha, com livre acesso a sal mineral e água de córrego. A quantidade e qualidade da forragem nesse piquete eram insatisfatórias, pois o período chuvoso havia começado de cinco a dez dias antes, não havendo boa disponibilidade de volumoso para o lote. A pequena quantidade de capim existente era muito seca. $\mathrm{Na}$ inspeção do piquete, observou-se grande quantidade de plantas invasoras, com destaque para uma espécie de planta, que apresentava ampla disseminação com grande quantidade de plantas adultas em frutificação (Figura 1) e brotos (Figura 2) com sinais de terem sido ingeridas pelos animais. Posteriormente, essa planta foi identificada por especialistas do herbário da UFT como Combetum glaucocarpa, com número de registro HTO:10509.

Cerca de dez dias após a colocação dos animais no piquete, observaram-se sinais de intoxicação, com a morte de 3 a 5 animais por dia, totalizando 20 óbitos e 43 animais com alterações clínicas visíveis. Recomendou-se a transferência dos animais para outro piquete com boa disponibilidade de forragem e sem a presença da planta suspeita. As mortes só cessaram 25 dias após essa ação e, no decorrer desse período, registrou-se a morte de 50 animais, somando um total de 70 mortos. Ressalta-se que todos os animais com alterações clínicas visíveis morreram (morbidade de 35\% e letalidade de 100\%). O surto perdurou por 32 
dias. Os principais sinais clínicos observados nos animais foram edema na região posterior da coxa, região inguinal, períneo e escroto, em alguns se estendendo à parte ventral do abdômen, tórax e barbela (Figura 3), fezes escuras e fétidas (melena), emagrecimento acentuado, pelos ásperos e apatia. Alguns animais apresentaram secreção nasal de aspecto catarral, com odor fétido. Dos dez animais examinados clinicamente, seis apresentavam sons abafados à auscultação do tórax, três tinham atonia ruminal e dois estavam com hipotermia. O curso clínico variou de 3 a 20 dias. Todos os animais avaliados apresentavam acentuada elevação dos níveis séricos de uréia, creatinina, das atividades séricas de ALT e AST e diminuição dos níveis séricos de PPT e das globulinas (Quadro 1).

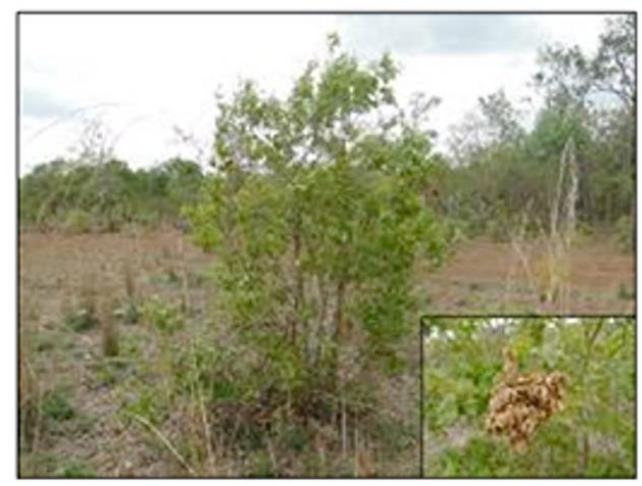

Figura 1. Combretum glaucocarpa adulta na pastagem. No detalhe: frutos maduros da planta.

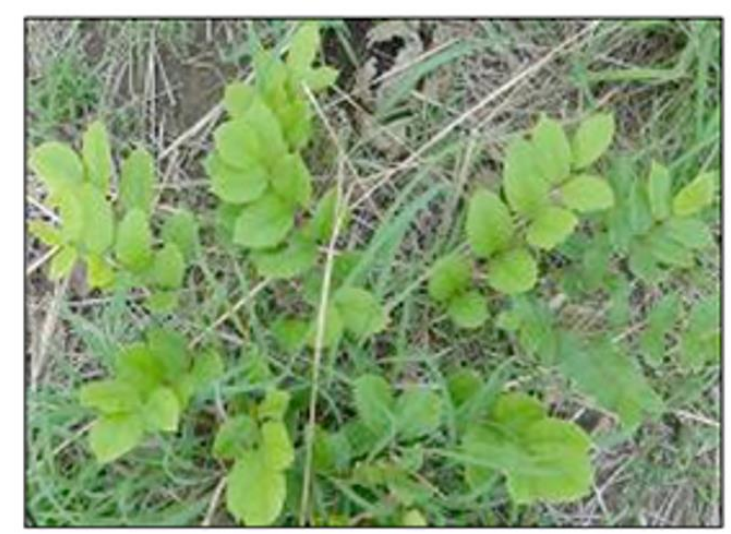

Figura 2. Broto de Combretum glaucocarpa, na Pastagem onde ocorreu o surto.

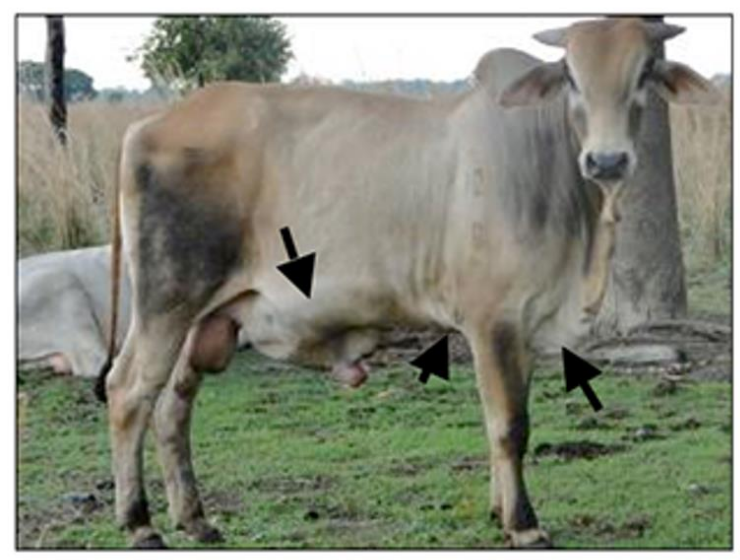

Figura 3. Bovino intoxicado por Combretum glaucocarpa, no qual se observa edema subcutâneo na região ventral do abdômen, tórax e barbela (setas). 
Quadro 1. Valores de atividades de ureia, creatinina, ALT, AST, albumina e PPT em bovinos intoxicados espontaneamente por Combretum glaucocarpa no Estado do Tocantins

\begin{tabular}{|l|c|c|c|}
\hline \multicolumn{1}{|c|}{ Parâmetros } & Valores de referência & Média + desvio padrão & $\begin{array}{c}\text { Amplitude de } \\
\text { variação }\end{array}$ \\
\hline Ureia (mg/dL) & $20-30$ & $160,6+90,80$ & $42-88$ \\
\hline Creatinina (mg/dL) & $1-2,0$ & $11,66 \pm 8,0$ & $5,25-24,1$ \\
\hline ALT (UI/L) & $14-38$ & $57,4 \pm 18,88$ & $41-94$ \\
\hline AST (UI/L) & $20-34$ & $106,8 \pm 60,74$ & $60-225$ \\
\hline PPT (g/dL) & $6,7-7,5$ & $5,61 \pm 0,63$ & $4,65-6,37$ \\
\hline Albumina (g/dL) & $3,0-3,6$ & $4,01 \pm 1,02$ & $2,78-5,25$ \\
\hline Globulina (g/dL) & $3,0-3,6$ & $1,57 \pm 0,53$ & $0,95-2,25$ \\
\hline
\end{tabular}

Fonte: Meyer et al. ${ }^{(5)}$.

Macroscopicamente, foram observados edemas nas regiões subcutâneas na parte ventral da barbela, tórax e abdômen, na região inguinal, no períneo e no escroto. Durante a necropsia, observou-se excesso de líquido seroso citrino na cavidade abdominal (cerca de 15 litros), cavidade torácica (cerca de 6 litros) e saco pericárdico (cerca de 3 litros). Identificou-se edema na bexiga, tecidos perirrenais e na subserosa da vesícula biliar junto à sua inserção ao fígado. Foi observado fígado aumentado de tamanho com bordos arredondados, congesto e azulado. Petéquias e equimoses foram observadas no epicárdio, miocárdio, mucosa da traqueia, omento, serosa do rúmen, vesícula urinária e testículos. Áreas de sufusões foram observadas no encéfalo.

Na microscopia, o fígado apresentou vacúolos intracitoplasmáticos e tumefação nuclear centrolobular moderada. No rim, observaram-se focos de hemorragia na junção corticomedular com degeneração tubular e na grande maioria dos túbulos foram encontradas células epiteliais necróticas com cilindros hialinos. As células epiteliais estavam transformadas em massas eosinófilas amorfas que preenchiam os túbulos. Externamente, os túbulos estavam delimitados apenas pela membrana basal (Figuras 4 e 5).

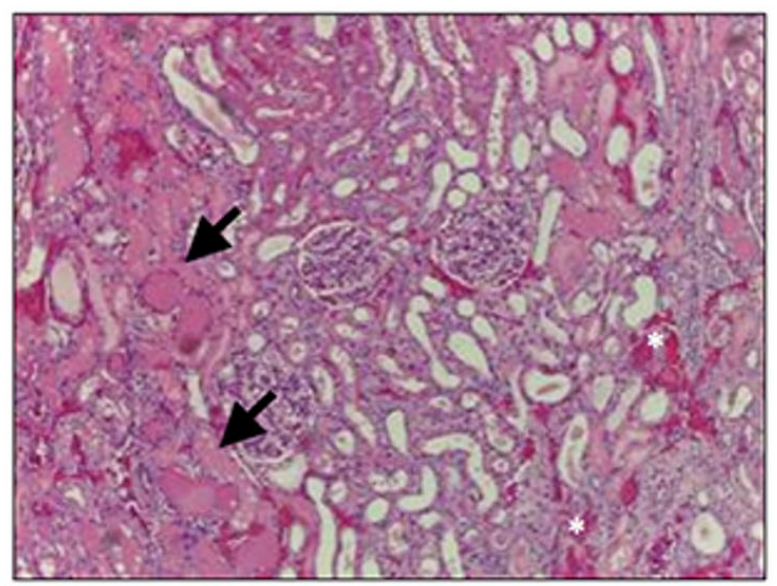

Figura 4. Rim com focos de hemorragia e congestão na junção corticomedular(*), grave degeneração tubular, alguns túbulos com células epiteliais necróticas e cilindros hialinos (setas). H.E. Obj. 10x. 


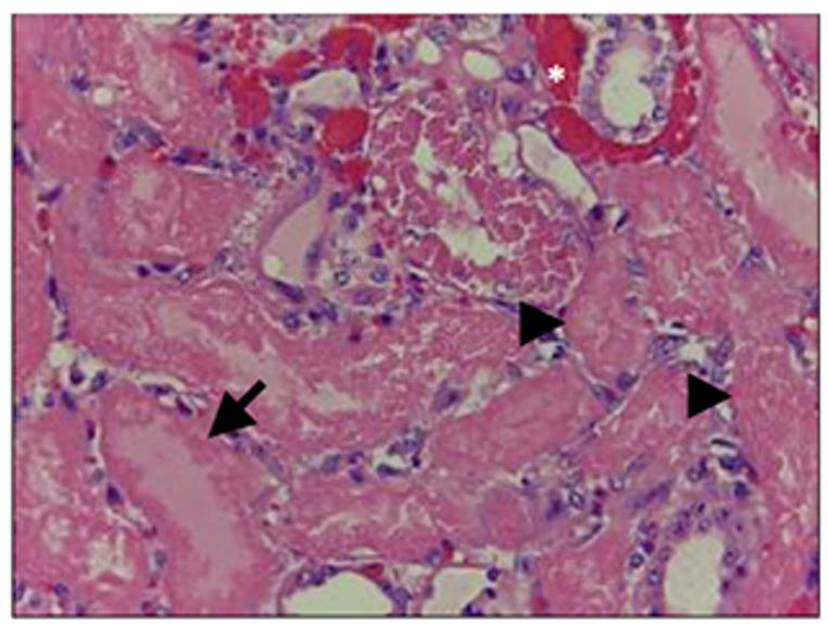

Figura 5. Rim com focos de hemorragia e congestão na junção corticomedular(*), grave degeneração tubular, a maioria dos túbulos com células epiteliais necróticas e cilindros hialinos (setas). As células epiteliais estão transformadas em massas eosinófilas amorfas que preenchem os túbulos, externamente os túbulos estão delimitados apenas pela membrana basal (cabeça de seta) H.E. Obj. 40x.

\section{Discussão}

O diagnóstico de intoxicação por Combretum glaucocarpa baseou-se no quadro clínico, achados de necropsia e lesões histológicas apresentadas pelos animais, além da identificação da planta na pastagem. Os sinais clínicos nos bovinos intoxicados no presente estudo foram principalmente de natureza renal e hepática e semelhantes aos notados nos surtos de intoxicação natural nos Estados do Piauí e Ceará por Tokarnia et al. ${ }^{(2)}$, bem como os sinais descritos por Silva ${ }^{(4)}$ em seus estudos experimentais feitos com bovinos intoxicados por essa planta.

Apesar de as alterações macro e microscópicas observadas neste estudo serem muito semelhantes aos relatos de intoxicação natural e experimental por $C$. glaucocarpa em bovinos feitos por Tokarnia et al. ${ }^{(2)}$ e Silva ${ }^{(4)}$, a sufusão no encéfalo observada no animal necropsiado não havia sido relatada anteriormente nesse tipo de intoxicação. As alterações renais são explicadas pela natureza nefrotóxica da planta, com degeneração tubular e formação de cilindros intraluminais, levando a um quadro de insuficiência renal que, por sua vez, aumenta os níveis de ureia e creatinina. O aumento dos níveis de ureia pode induzir a várias alterações, entre elas interferir nos fatores de coagulação e na permeabilidade dos vasos, resultando em quadros de hemorragias, como sugere Radostits et al. ${ }^{(6)}$.

A elevação das atividades séricas das enzimas renais e hepáticas foi compatível com a grave lesão ao rim e fígado detectadas nos exames macro e microscópico, também executados por Meyer et al. ${ }^{(5)}$ e Radostits et al. ${ }^{(6)}$. A diminuição das PPT em todos os animais avaliados ocorreu provavelmente em decorrência da perda de proteínas por via renal, situação comum em casos de insuficiência renal aguda, demonstrada por Meyer et al. ${ }^{(5)}$. As alterações encontradas nas concentrações da albumina e da globulina também se devem a esse fator, uma vez que se observou a presença de albumina na urina dos bovinos intoxicados experimentalmente pela C. glaucocarpa, como mostrou Silva ${ }^{(4)}$. De fato, a diminuição das proteínas séricas é encontrada em doenças renais, má nutrição, albuminúria e doenças hepáticas terminais, com base nos estudos de Meyer et al. ${ }^{(5)}$. Portanto, as reduções das proteínas séricas observadas no presente estudo provavelmente estão relacionadas ao dano renal e secundariamente ao dano hepático, ambos causados pelo consumo da planta. 
O surto ocorreu na região central do Estado do Tocantins, Norte do Brasil. Combretum glaucocarpa é descrita por Tokarnia et al. ${ }^{(2)} \mathrm{e}$ Riet-Correa et al. ${ }^{(7)}$ como uma das plantas tóxicas mais importantes na região Nordeste, principalmente nos Estados do Piauí, Ceará e Bahia. Até o presente momento, não há relatos sobre a ocorrência da $C$. glaucocarpa bem como casos espontâneos de intoxicação em bovinos por essa planta no Estado do Tocantins e/ou na Região Norte do Brasil.

O período de ocorrência (início das chuvas) e evolução clínica de 3 a 20 dias corroboram com o descrito por Tokarnia et al. ${ }^{(2)}$, que descreveram uma evolução subaguda, em torno de 5 a 20 dias, por vezes, casos com evolução mais rápida. Silva ${ }^{(4)}$ relatou em seus experimentos evoluções que variaram de 2 a 37 dias, portanto mais longas que as observadas em nossos estudos. A morbidade de $35 \%$ e a letalidade de $100 \%$ foram maiores do que os relatadas por Tokarnia et al. ${ }^{(2)}$. Recomenda-se o diagnóstico diferencial com algumas doenças que cursam com quadro clínico-patológico igual ou semelhante ao causado pela intoxicação por $C$. glaucocarpa, como a intoxicação pelas favas de Dimorphandra spp., o que não é difícil, pois esse tipo de intoxicação não ocorre no início das chuvas, e sim na época da seca, quando as favas da planta caem no chão e são ingeridas pelos animais; Amaranthus spp. ocorre em todo Brasil, porém não foi encontrada na propriedade onde ocorreu o surto; Metternichia princeps, planta com distribuição restrita à Mata Atlântica, desde o Rio de Janeiro até a Bahia, de acordo com Tokarnia et al. ${ }^{(1)}$. Devem ser considerados ainda outros agentes nefrotóxicos, como os aminoglicosídeos e os metais pesados, que podem levar ao desenvolvimento de necrose tubular, tendo base as pesquisas de Radostits et al. ${ }^{(6)}$ e Oliveira et al. ${ }^{(9)}$. Além de essas situações serem raras, a doença não ocorreria em surtos e sim casos isolados. Com base no histórico e nas observações clínico-patológicas e epidemiológicas, concluiu-se que os animais não tiveram acesso a essas substâncias. Atualmente não há tratamento eficaz para esse tipo de intoxicação e a profilaxia deve consistir em retirar o gado das áreas infestadas pela planta, principalmente após a primeira chuva, por aproximadamente um mês.

\section{Conclusão}

Com base nos achados epidemiológicos (presença da planta, evolução do quadro e época do ano), e nos achados macroscópicos (edema subcutâneo e edema e hemorragia em diversos órgãos) e microscópicos (alterações hepáticas e renais), concluiu-se que os animais foram intoxicados por Combretum glaucocarpa.

\section{Referências}

1. Tokarnia CH, Dobereiner J, Peixoto PV. Plantas Tóxicas do Brasil para Animais de Produção. Rio de Janeiro: Helianthus. 2012;(2):586.

2. Tokarnia CH, Dobereiner J, Peixoto, PV. Intoxicação de bovinos por Thiloa glaucocarpa (Combretaceae), no Nordeste do Brasil. Pesquisa Veterinária Brasileira. 1981:1(4);111-132.

3. Riet-Correa F, Medeiros RMT, Tokarnia CH \& Dobereiner J. Toxic plants for livestock in Brazil: Economic impact, toxic species, control measures and public health implications. In: Panter KE, Wierenga TL \& Pfister JA. Poisonous Plants: Global research and solutions. CAB International: Wallingford; 2007. p. 2-14. English.

4. Silva SV. Aspectos clínicos, laboratoriais e anátomo-histopatológico na intoxicação experimental por sipaúba (Thiloa glaucocarpa Eichl.) em bovinos no Estado do Piauí [tese de mestrado]. [Recife (PE)]: Universidade Federal de Pernambuco; 1987. 89 p. 
5. Meyer DJ, Coles EH \& Rich LJ. Medicina de laboratório veterinário: Interpretação e diagnostico. 1st ed. São Paulo: Roca; 1995. 308p. Portuguese.

6. Radostits OM, Gay CC, Blood DC, Hinchcliff KW. Clínica Veterinária: um tratado de doenças dos bovinos, ovinos, suínos, caprinos e eqüinos, 9th ed. Rio de Janeiro: Guanabara Koogan; 2002. 1737p. Portuguese.

7. Riet-Correa F, Medeiros, RMT \& Dantas AFM. Plantas Tóxicas da Paraíba. Centro de Saúde e Tecnologia Rural, Patos. SEBRAE: PB; 2006. 58p. Portuguese.

8. Mello GWS, Oliveira DM, Carvalho CJS, Pires LV, Costa FAL, Riet-Correa F \& Silva SMMS. Plantas tóxicas para ruminantes e eqüídeos no Norte Piauiense. Pesquisa Veterinária Brasileira. 2010; 30(1):1-9.

9. Oliveira JFP, Cipullo JP \& Burdmann EA. Nefrotoxicidade dos aminoglicosídeos. Brazilian Journal Cardiovascular Surgery. 2006; 21(4):444-452. Portuguese. 